\title{
Modernity Problems of Sandu Shui Nationality Needlework
}

\author{
Wenting Liu ${ }^{1,2}$ \\ ${ }^{1}$ Art College of Sichuan University, Chengdu of Sichuan Prov.650059, China; \\ ${ }^{2}$ Applied Nuclear Technology and Automation Engineering College of Chengdu University of \\ Technology, Chengdu of Sichuan Prov.650059, China \\ kkllooo@hotmail.com.
}

Keywords: Sandu Shui nationality; folk needlework; modernity

\begin{abstract}
By taking Shui nationality needlework as the study case, this thesis observes the modernity problems of Shui nationality needlework from the perspective of the formation reasons of needlework modernity and the modernity features of needlework. It points out the necessity of the formation of Shui nationality needlework modernity as a result of overlapping outcomes of natural geography, female identity, policy influences and other factors. Furthermore the modernity features of Shui nationality needlework characteristic of new intense national and visual life paradigm.
\end{abstract}

\section{Introduction}

With the general population of 428972 (2010), Shui nationality is mainly distributed in Buyi and Miao Autonomous Prefecture of QianNan , and Miao Dong Autonomous Prefecture of QiandongNan in Guizhou province, Nandan, Huanjing, Hechi, Rongshui and Duan in Guangxi Province and Fuyuan county in Yunan province. Shui nationality has a long history, multiple varieties of needlework and solid mass foundation. Until January 2015, Sandu Shui National Autonomous County had three items listed in National Intangible Cultural Heritage represented by "Shui Nationality Customs", "Shui Nationality Horsetail Embroidery" and "Shui Nationality Duan Festival", thirteen items listed in Provincial Intangible Cultural Heritage, fourteen items listed in State Intangible Cultural Heritage and forty-seven items listed in County Intangible Cultural Heritage.

Along with the modernization, the Shui nationality needlework is in the transformation period: the relationship among traditional value division, needlework function endowed by female selfindependence and society turns increasingly complicated and obscure. The resulting series of new problems force people to make response in theoretical and practical level. In view of the formation reasons of modernity, the study on the features of Shui nationality needlework proves to be more essential.

\section{2. the Generation of Sandu Shui Nationality Needlework Modernity}

The formation causes of the generation of Shui nationality modernity should be attributed to the separation between primitive time and space and reorganization of form. This will be specifically analyzed in the following three aspects.

\subsection{Favorable Geographical Location and Advanced Rice Agriculture}

Shui nationality mainly dwell in regions with convenient transportation conditions, such as Longjiang at the boundary between Guizhou and Gunagxi, and dam and hill districts on the upstream of Duliu River. As early as Tang and Song dynasty, the dwelling community presents the phenomenon of "growing rice like Hunan". The prosperity of rice agriculture not only offers material and technical foundation and inspiration source for needlework but also cultivates the primitive aesthetic outlooks of Shui nationality.

During the interaction with surrounding nationalities, Shui nationality constantly enriches the varieties and manufacturing techniques of needlework. In particular, the introduction of Han nationality culture exerts dominant functions on the reformation of the social structure of Shui nationality. Moreover,it also performs persistent and potent demonstration functions to some extent 
and generates key impacts on the formation of Shui nationality modernity.

\subsection{Great Change in Shui Nationality Female Identity and Decrease of Dependence on Male}

From the perspective of philosophy, the essence of modernity is the rationality of spontaneous reflection. As said by German philosopher Michel Foucault, "human being is the product derived in modern period and a fabrication made by rationality". As for Shui nationality, the awakening of female subjective consciousness is the important cause that promotes needlework modernity and the important supporting factor that propels following development.

In traditional family cultural mode, Shui nationality needlework exists on the premise of the "childbearing". Together with the popularity of immigrant labor in the 1980s, anti-illiteracy work targeted at Shui nationality females comprehensively started. Along with the expansion of recognition scope and activity range, Shui nationality females also improve their economic status. For instance, with the expansion of recognition scope, Shui nationality females will not unconditionally obey the clan rules and natural survival state but choose a free and self-conscious survival state. At the same time, their lifetime goal also transits from primitive child-bearing objective to self-value realization. With the improvement of economic status, Shui nationality females decrease the dependence on males and begin to have absolute right in article design ideas and practical operation as the main subjects. This implies that Shui nationality needlework obtains relatively free ideas and selection rights. Such rights make the generation of modernity become possible. Furthermore, the variation of status and identity, the combat with tradition and customs, and the advent of science, technology and rationality open the gate for Shui nationality society. All of these not only lay the firm foundation for the expansion of scientific rationality, but also create opportunities for the birth of critical spirits in Shui nationality modernity.

\subsection{Policy Factors}

After 2000, the government in each dwelling community started to protect Shui nationality needlework through selecting inheritors and opening training classes. In addition to the great mobilization of folk initiative, the advent of foreign capital initiates the process of needlework commercialization. The intervention of the government shapes modernity as a rational socialgoverned cultural mode which could easily integrate into and operate the Shui nationality society. Later on, the modernity problem of Shui nationality needlework becomes an inevitable fact. The important components in needlework such as people, event and objectall changes and the heterogeneous elements in design are manipulated by rights and knowledge. Accordingly, traditional design courses are challenged.

As mentioned above, the integration between internal and external factors makes the generation and development of Shui nationality modernity become essential. Different factors have different formation causes, meanings, activity conditions and scopes. However, when they integrate into a whole, they will produce immeasurable functions on the formation of Shui nationality needlework rooted in traditional culture.

\section{Chapter Two Modernity Features of Sandu Shui Nationality Needlework}

\subsection{Visualized Aesthetic Taste}

The commercialization tendency in modern times expands the audiences of Shui nationality needlework from national communities to external world. Moreover, the deviation of needlework aesthetics from traditional standards and the transition of needlework from spirits to forms greatly intensify visual experience.

The modern aesthetics of Shui nationality weakens the intangible national symbol expressions and make restructure through integrating modern design languages into the butterfly tattoo, thunder tattoo, book tattoo and folwer tattoo and other of visible symbols (fig.1). The emphasis on Shui nationality aesthetic functions makes the quality of visual experience become the primary determinant factor that decides the success of needlework. The most typical example is that the tattoo originally has words utility will be understood as color brightness and shape beauty problems in the mind of external audiences. The emphasized visual features are important manifestation of image consumption of Shui nationality needlework in contemporary times. The resulting needlework aesthetics gradually 
conforms to popular public aesthetics and the dual relationship between manufacturers and market turns increasingly prominent. Accordingly, the increasingly prominent commercialization tendency of needlework fosters more new needlework varieties.

Visualization brings about a new trend for the aesthetics of Shui nationality needlework. At the same time, it also changes the formation mechanism of the aura. The time of appreciation changes from eternity to instant and focus on specific visualized spot. The final determination of the spot depends on the combat between family factors and market factors. During the perception process of people for needlework visualization, the point attracts the attention of consumers and stimulates their desire of purchase and final consumption. Such stimulation is bi-directional since it on the one hand stimulates needlework producers to interpret the market with their own manners, make expressions with visualized languages and recreate traditional needlework with modern aesthetic awareness in consistency with modern life. For instance, English letters are used for decoration and some fans are made with cartoon figures such as Xiyangyang which is a very famous cartoon character in China. On the other hand, visual stimulation satisfies the needs for freshness and visual functions of people. Such reformation is the representative of innovation in the eyes of national people and simultaneously the endorsement of "national spirits" easily accessible to external people.

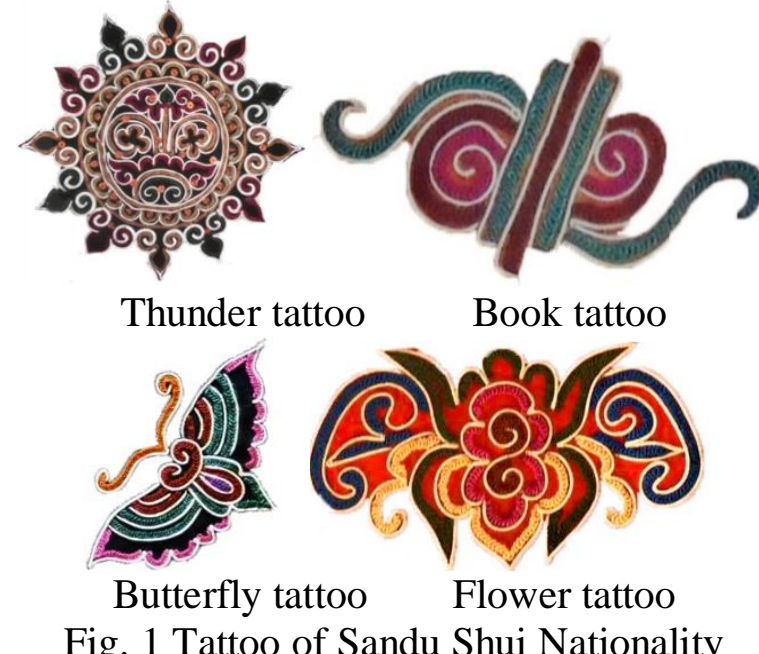

Fig. 1 Tattoo of Sandu Shui Nationality

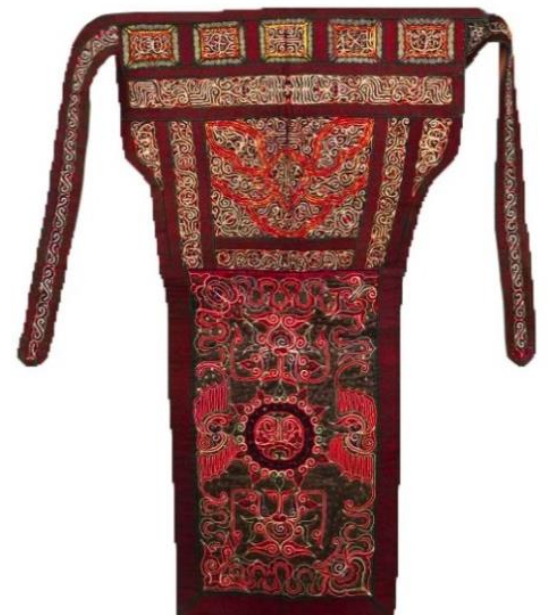

Fig. 2 Beishan of Sandu Shui Nationality

\subsection{The Obscurity of National Boundary and the Intensification of "Symbolic Features"}

Modernity does not exist together with absolute national division. The similarity of folk needlework in production concepts, production forms and aesthetic pursuits propels Sandu Shui nationality to enhance its own symbolic features.

Every technique conforms to the law of nature in essence. The obscure boundary among nationalities mostly exists in the level of crafts and ideas. One example is material innovation. For instance, the replacement of fishing line by horse tail as the central line and the replacement of traditional vegetation by chemical paint are the adaptation to industrial production. It also gives 
needlework a new material characteristic. Technical integration, the reference of Bouyei Beishan(a kind of Embroidered Swaddle for women to carry baby on the back) making techniques, the learning of Han nationality embroidery methods all improve Shui nationality needlework in color and texture. Besides, the integration of computer technology makes the transformation of imagination into reality much easier and accordingly promotes the generation of needlework.

Modernity is consciously eliminating the boundary between tradition and customs and the boundary between life and art. For instance, the insertion embroidery Baishan of Bouyei nationality has developed into one branch of Shui nationality known as Daiyi (fig.2). In modern times, the formation and techniques of traditional needlework start to shake off fixed relationship which could offer a limited recreation space for both manufacturers and designers. Until now, the adaptation of Shui nationality to the new environment far exceeds the determination in traditional sense. In this circumstance, how to maintain the primitive state of Shui nationality needlework becomes rather important. Furthermore, the symbolic meaning of Shui nationality needlework also turns significant.

\subsection{The Combat between Traditions and Customs: New Writing Paradigm}

The combat between traditions and customs is actually a subtle symbiotic relationship. If original Shui nationality needlework is the record of traditional life characterized by child-bearing and labor work, then Shui nationality needlework in modern times gradually deviates from daily life and experiences the transformation from past conventions to rationality and undertakes certain secular salvation functions. Since social activities separate from primitive regional context and go back to daily life after artificial rational abstraction, it becomes a new paradigm of life with artistic temperament.

In the investigation, Wei Yingli, the President of Shui Nationality Horsetail Embroidery Association in Sandong Village, Sandu County once told the author that the original intention of this association was to teach needlework skills to females. Besides the earning of economic values, it more importantly delivers national culture, connects villages and cities and allows later generations to sense the implied meanings and enhance national identity. The needlework and embroidery of Wei Yingli obviously show the critical reflections for traditional culture and the new vigor after shaking off original restraints.

Shui national needlework creation with modernity features on the one hand presents the familiarity and flexible application of modern design languages and endows needlework with the sense of modernity. On the other hand, needlework constantly retrieves the essence of valuable entities or ideologies from the tradition of Shui nationality and makes compensation for the loss of highefficiency and feasibility in modern life. The combination between past and present with the modern means has fundamental difference from simple simulation. This is also the meaning of new life mode created by Shui nationality needlework.

\section{Conclusion}

Modernity is a concept with multiple connotations and contentions as the guidance in cultural mode and spiritual mode in present society. Modernity problems seem to be inevitable. In particular, when it comes to the study on the pursuit for modernity of individuals, the meaning turns more apparent. By taking Shui nationality needlework as the study case, this thesis observes the modernity problems of Shui nationality needlework from the perspective of the formation reasons of needlework modernity and the modernity features of needlework. It points out the necessity of the formation of Shui nationality needlework modernity as a result of overlapping outcomes of natural geography, female identity, policy influences and other factors and the modernity features of Shui nationality needlework characteristic of new intense national and visual life paradigm. To be sure, folk art filled with modernity features is not simple technique inheritance and proportional elaboration problems. This thesis aims to offer references for the protection and recreation of folk art of minority nationalities in new times. 


\section{Acknowledgments}

Thanks for the help from Ms Wei Yingli, the inheritor of Shui nationality horsetail embroidery and the President of Shui Nationality Horsetail Embroidery Association in Sandong Village, Sandu County, in the research period.

Cited from The List of Intangible Cultural Heritage in Sandu Shui National Autonomous County; original data from State Council Census Office, Population and Employment Statistics Department in National Bureau of Statistics. Population Census Materials of China in 2010 [M[. China Statistics Press, 2012

\section{References}

[1]. Pan Zhaolin. The Study of China Shui Nationality Culture [M]. Guizhou People's Press, 2004.

[2]. The compilation team of The Brief History of Shui Nationality. The Brief History of Shui Nationality [M]. Guizhou People's Press, 2008.

[3]. Luo Shibin. Sandu Shui National Autonomous Annals [M]. Guizhou People's Press, 1992.

[4]. Fang Lili. Contemporary Constitution of Western Folk Art [J]. The Study of Art, 2005. 